\title{
Evolution of Service: Importance, Competitiveness and Sustainability in the New Circumstances
}

\author{
Abu Saleh Md. Sohel-Uz-Zaman ${ }^{1}$, Umana Anjalin ${ }^{2}$ \\ ${ }^{1}$ School of Business, United International University, Dhaka, Bangladesh; ${ }^{2}$ Department of Business Administration, The University \\ of Asia Pacific, Dhaka, Bangladesh. \\ Email: sohelzaman@gmail.com, sohelzaman2003@yahoo.co.uk
}

Received April $9^{\text {th }}, 2011$; revised June $20^{\text {th }}, 2011$; accepted July $3^{\text {rd }}, 2011$.

\begin{abstract}
In the complex business word, service is increasingly getting the centre stage in the economies across the world. The exponential necessity of innovative service in one hand is providing excellent opportunity and on other hand, posing a number of challenges to the firms. In this circumstance, the policy makers of the businesses are aware about the challenges and are keenly interested to develop a general strategy which will enhance their competency in rapidly changing business context. They are actively trying to identify the resources and competencies that are necessary for their competitiveness. This study will investigate and examine the factors that are responsible for the growth of service sector in the increasingly complex business world and propose a strategic direction to harness the competitive edge by configuring their resources with the help of real world example; especially, in developing country context. Growth and sustainability through innovative service is the central theme of this paper.
\end{abstract}

Keywords: Strategy, Resources, Service, Competency, Competitive Advantage, Innovation Technology, Knowledge and Network

\section{Introduction}

The foremost characteristic of today's economy is that, it is influenced by many socio-economic factors. Customers are more conscious about their right and privilege along with increased demand for customized service. Organizations are also aware of the increased dominance of customers over the economy. In such a situation, service has become an essential issue for companies. Companies are now offering both the goods and services together in one package. This business phenomenon can be called as "the servitization of business" [1]. The change not only has influenced manufacturing organizations but also the economies across the world. As a result, the popularity and necessity of service has been increased exponentially. This new circumstance, in one hand, has provided excellent opportunities for growth of the business with the help of value added service on the other hand, has exposed a range of challenges that they (firms) have to be tackled efficiently. The leaders of these organisations are quite aware of them. They are concerned in maintaining the competitiveness of their organisations through a more value added service along with the core product.

\section{Objective and Scope}

The core objective of this paper is to develop a general strategic direction for innovative service in developing countries in order to enhance their competitiveness and ensure long-term sustainability. Various contemporary issues in service like technology, changes in demography, socio-economic condition, innovation, knowledge management, network, etc. will be critically examined to have an in depth understanding of the complex nature of modern business scenario since these are the key forces of the evolution of service sector in world economy. These issues (key forces) will be analyzed and interpreted in reference to the real world examples in developed and developing countries. Due to the globalization and free economy, the economies in the developed and the developing countries are now more interactive than that of any time before. In this paper, the role of service in national and international business has been highlighted in order to demonstrate the growing influence of service in our national economy. The context of this paper is developing countries; mainly in South-East Asia and in particular China and Bangladesh. 


\section{Growing Importance of Service in National and International Economy}

At present, service is one of the crucial factors of competitive advantage in many industries across the world. Initially, it was believed that service itself is not productive. Even the founding father of Economics Adam Smith stated in his book, The Wealth of Nations, that among the service, labor is only productive if it increases the value of item for which the labor is deployed [2]. Initially there was a fear that the growth in service sector would gradually diminish manufacturing sector and hence the economic growth. Therefore, the services that are not utilized for the production of tangible goods are not considered as productive rather those are considered as operating costs. The scenario has been changed gradually from the beginning of the twentieth century especially, in the developed nations. In 1950 it was precisely learned that in world economy service sector became the major contributor to GDP [3]. In creating job and increasing gross domestic products service industries are now the largest contributors in many countries (Table 1) [4]. This fact has compelled scholars to realize the magnitude of service sector in the economies. Many new industries have been emerged due to the boom in the necessity of service. Economic activities such as transportation, communication, construction, infrastructure, tourism, public administration, restaurants, hotels, storage, defense, trade, banking, insurance, financing, real estate, social and personal services, business services, community services, etc.-all are included in service sector.

The contribution of service in income generation, employment creation, and foreign exchange earnings has increased significantly over the last two decades; between 1990 and 2006, the share of service in GDP grew continuously from 65.4 percent to 73.0 percent in developed countries and, from 49.6 percent to 50.8 percent in developing countries; service now account for about 72 than that of developed countries (Tables $2 \& 5$ ) [4]. In a recent statistical year book of UNCTAD it is indicated

Table 1. Contribution of service sector to nominal GDP in developed economies (\%).

\begin{tabular}{lcccc}
\hline Country & $\mathbf{1 9 9 0}$ & $\mathbf{1 9 9 5}$ & $\mathbf{2 0 0 0}$ & $\mathbf{2 0 0 8}$ \\
\hline USA & 70.6 & 72.6 & 75.4 & 77.1 \\
Canada & 65.9 & 66.4 & 64.5 & 68.5 \\
UK & 64.2 & 67.5 & 71.8 & 75.6 \\
Germany & 61.2 & 66.6 & 68.5 & 69.0 \\
France & 69.6 & 72.1 & 74.3 & 77.6 \\
Italy & 64.4 & 66.4 & 68.8 & 71.0 \\
Japan & 59.1 & 64.9 & 67.2 & 69.7 \\
Australia & 66.2 & 67.8 & 69.9 & 68.7 \\
\hline
\end{tabular}

Source: UNCTAD Handbook of Statistics (2010).
The importance of service in developing countries like India, China, etc. is also increasing but at a slower pace that there is a clear increasing trend of service export and import in all over the world in recent years (Table 3 \& Table 4) [4] and 35 percent of employment in developed and developing economies respectively [5].

From the abovementioned tables it is clear that the role

Table 2. Contribution of service sector to nominal GDP in developing economies (\%).

\begin{tabular}{lllll}
\hline Country & $\mathbf{1 9 9 0}$ & $\mathbf{1 9 9 5}$ & $\mathbf{2 0 0 0}$ & $\mathbf{2 0 0 8}$ \\
\hline China $^{*}$ & 34.3 & 33.7 & 38.4 & 40.1 \\
India & 42.5 & 45.2 & 50.4 & 52.4 \\
Thailand & 49.7 & 49.0 & 49.0 & 43.8 \\
Bangladesh & 47.7 & 49.1 & 49.2 & 52.3 \\
Pakistan & 49.2 & 51.1 & 51.9 & 52.9 \\
Sri Lanka & 44.9 & 49.4 & 52.5 & 54.6 \\
Nepal & 40.5 & 44.5 & 46.1 & 50.7 \\
\hline
\end{tabular}

${ }^{*}$ China mainland excluding Hong Kong SAR, Macau SAR and Taiwan Source: UNCTAD Handbook of Statistics (2010).

Table 3. Value of export of service [millions of dollars].

\begin{tabular}{lccccc}
\hline Economy & $\mathbf{2 0 0 5}$ & $\mathbf{2 0 0 6}$ & $\mathbf{2 0 0 7}$ & $\mathbf{2 0 0 8}$ & $\mathbf{2 0 0 9}$ \\
\hline Developed & 625,344 & 726,127 & 881,628 & $1,000,268$ & 902,545 \\
Economy & & & & & \\
Developing & $1,877,385$ & $2,102,916$ & $2,496,699$ & $2,777,158$ & $2,419,806$ \\
Economy & 74,404 & 91,999 & 122,206 & 147,112 & 129,500 \\
China* $^{*}$ & 52,527 & 69,730 & 86,965 & 102,949 & 91,106 \\
India & 20,163 & 24,822 & 30,357 & 33,3833 & 30,198 \\
Thailand & 3678 & 3506 & 3767 & 4262 & 4106 \\
Pakistan & 1249 & 1334 & 1617 & 1996 & 1944 \\
Bangladesh & 1540 & 1625 & 1775 & 2002 & 1892 \\
Sri Lanka & 380 & 386 & 511 & 724 & 652 \\
Nepal & 380 \\
\hline
\end{tabular}

${ }^{*}$ China mainland excluding Hong Kong SAR, Macau SAR and Taiwan. Source: UNCTAD Handbook of Statistics (2010).

Table 4. Value of import of service [millions of dollars].

\begin{tabular}{lccccc}
\hline Economy & $\mathbf{2 0 0 5}$ & $\mathbf{2 0 0 6}$ & $\mathbf{2 0 0 7}$ & $\mathbf{2 0 0 8}$ & $\mathbf{2 0 0 9}$ \\
\hline $\begin{array}{l}\text { Developed } \\
\text { Economy }\end{array}$ & 703,086 & 817,782 & 989,988 & $1,161,796$ & $1,061,439$ \\
Developing & $1,690,190$ & $1,845,496$ & $2,139,426$ & $2,373,931$ & $2,084,228$ \\
Economy & & & & & \\
China & 83,796 & 100,833 & 130,111 & 158,924 & 158,900 \\
India & 47,287 & 58,696 & 70,545 & 87,896 & 74,387 \\
Thailand & 27,027 & 33,015 & 38,425 & 46,259 & 38,038 \\
Pakistan & 7508 & 8418 & 8811 & 9715 & 7488 \\
Bangladesh & 2207 & 2340 & 2885 & 3664 & 3405 \\
Sri Lanka & 2089 & 2394 & 2602 & 3010 & 2522 \\
Nepal & 435 & 493 & 723 & 852 & 785 \\
\hline
\end{tabular}

*China mainland excluding Hong Kong SAR, Macau SAR and Taiwan. Source: UNCTAD Handbook of Statistics (2010). 
Table 5. Annual average growth rates of total and per capita real gross domestic product (\%).

\begin{tabular}{lcccccc}
\hline Economy & $\mathbf{2 0 0 4}$ & $\mathbf{2 0 0 5}$ & $\mathbf{2 0 0 6}$ & $\mathbf{2 0 0 7}$ & $\mathbf{2 0 0 8}$ & $\mathbf{2 0 0 9 ( e ) ~}$ \\
\hline China $^{*}$ & 10.1 & 10.4 & 11.6 & 13.0 & 9.0 & 8.7 \\
India & 8.3 & 9.3 & 9.7 & 9.1 & 7.3 & 5.7 \\
Thailand & 6.3 & 4.6 & 5.2 & 4.9 & 4.8 & -2.3 \\
Pakistan & 7.7 & 6.2 & 6.0 & 6.0 & 6.0 & 2.0 \\
Bangladesh & 6.3 & 6.0 & 6.6 & 6.4 & 6.2 & 5.4 \\
Sri Lanka & 5.4 & 6.2 & 7.7 & 6.8 & 6.0 & 3.5 \\
Nepal & 3.1 & 3.7 & 3.2 & 4.7 & 5.6 & 4.7 \\
\hline
\end{tabular}

${ }^{*}$ China mainland excluding Hong Kong SAR, Macau SAR and Taiwan. Source: UNCTAD Handbook of Statistics (2010).

and necessity of service is increasing across the world though the rate of contribution is varying in the developed and the developing countries. At present, service is an important source of economic growth; particularly in market economy. However, the export of service is less than the import of service in the developing countries in comparison to the developed countries. But this trend will change if the economies of these developing countries improve, i.e. export of service will be greater than the import of service and thus, the positive contribution to the GDP like developed countries will be ensured.

\section{Forces behind the Evolution of Service Sector}

Modern economies are dominated by service sector. It is impossible to say exactly when, how and why service started getting increased importance. Since the world war two, world economy has become more and more complicated. A dramatic change has been taken place in the composition of the economies across the nations. These changes could not be identified very precisely as significant service output is created from unrecorded household work, many hidden services in large corporations, associated service in the manufacturing sectors and so on [6]. For example, the contribution human resources functions, logistics, maintenance, etc. are not recorded or recognized accurately.

Various social, economic and technological factors, in addition to political factors have started influencing the firms more directly. It is quite difficult to say which factor(s) is responsible for the steady growth and popularity of service. In fact, there are a number of factors that have played a crucial role in this connection. Perhaps the most influential factor is the "need for service". In common, the factors are higher level of disposable income and customers' buying behavior, change in the demography, technological advancement, increase in the pace of globalization, intensification of professionalism, and changing nature of competitiveness of the businesses and as well as nations, etc.
Consumers' buying behavior changes as the disposable income changes. Famous statistician Ernest Engel observed a phenomenon, which is known as Engel's Law ${ }^{1}$. The people in the marginal level of the society spend almost their entire income for essentials like food and accommodation. But as the income increases, spending on the necessities decreases rather a tendency for spending in recreation, personal care and luxury increases. People with higher income spend relatively more on services and less on goods. A trend of economic development has been observed in many developing countries like China, India, Thailand and to some extent in Bangladesh, etc. in recent years. The increased joining of women in the workforce has brought a change in the domestic functions played inside the home. They are not confining themselves in traditional family territory. This has made a dramatic change in many developing countries. Women are now having less time for cooking and other household activities. In China, a large number of urban middle class have their breakfast, lunch and dinner in cheaper food corners or hotels since husband and wife both are working or involved in their income oriented activities (e.g. running grocery). Guardians are now more interested in sending their children in day care centers or day long school. Car owners are taking their cars for carwashes other than washing the cars by themselves. The standard of living has gone up with the increase in income. The rise in the number of dual career families also has created a greater demand for consumer services like housekeeping, retailing, real estate, tourism, personal finance services, etc. As a result, spending on entertainment, hospitality and tourism services has gone up.

Similar trend is also visualizing in Bangladesh. A large portion of garment workers are women. During this study several interesting facts came out. For example, they (garment workers) are sending their cloths to small laundries in their localities for washing since they have limited time to spare whereas, they used to wash those by themselves before. They buy their lunch from the food suppliers (caterer) at a cheaper rate. On the other hand, due to the economies of scale (as their number is quite large) they (food suppliers/caterer) can supply foods at a cheaper rate than the lower income restaurants for consumers. Increased disposable income gives rise to other from of business. With the dramatic increase in life expectancy, the world is now experiencing a rise in the population of retirees which, in turn has given rise to the new demand of leisure and travel, healthcare, insurance, and the like.

Consumers today are more demanding and not easily

${ }^{1}$ Engel's Law is the observed phenomenon that when a family's income increases, the proportion of money they spend on food decreases. 
contented with what they have. The aspiration level has also risen. The fast changing environment has forced to a greater competition and naturally, a greater demand for learning institutions, in order to hone and develop skills that are essential for the survival of the fittest. This has led to the opening of knowledge and information based services. The trend towards globalization and greater demand for communication, travel and information has nurtured growth in these services, which, in many cases have been brought about by the information superhighway and the advent of modern media and gadgetry. The increased specialization within the economy has directed to a dependence on specialist service providers like marketing communication or marketing research as supporting functional sectors of the economy. In this way, firms that at one time employed their own lawyers now use the services of law firms. The offering of cheap labor in the third world countries have given rise to the service called "outsourcing" which, with the help of state-of-the-art communication system does not require the mother company and the supporting outsourcing company to be located in the same country.

There is no disagreement that the technological progress is the single most influential factor. The technological-evolution has changed the dimension of service radically, especially the way the service is configured and delivered to the customers. Traditional banking service has been changed in many developing countries. Automated Teller Machine (ATM) or Instant Cash Booths are now available in all major cities in Bangladesh. As a result, the number of account holders in private banks has increased more than that of the government owned commercial banks. In counties like China, India, Bangladesh, with the help of information technology, all banks irrespective public or private sector, have a huge network; an account holder of any bank can use his or her ATM card or instant cash card in any bank in any place at any time all over the country. The new technology has not only modified the service package but also aided in obtaining economies of scale and a new scope of business with little additional cost [7].

\section{Strategic Importance of Service in Business}

Today firms compete on the basis of services, and not on the basis of physical products [8]. Service is the key determinant of competitive advantage since products are quite difficult to differentiate. Traditional manufacturing sector is gradually being overshadowed by the rise of service sector. Customers are no longer satisfied with the physical products alone. At the same time, since products are so similar in terms of feature and performance and therefore, customers often cannot differentiate the prod- ucts. In such a situation, embedded service is the one of the key determinants in differentiating products. Marketers are trying to attract customers by providing higher level of service than that of their competitors [9]. For example, to a customer, there is no apparent difference between a TCL television and a Konka television; it is the service that is offered by the retail store really differentiates these two products. In 1985, there was an interesting advertisement by IBM. The slogan of that advertisement was "If everybody wants to have an IBM terminal, it is because IBM service is the best". This advertisement did not highlight the tangible product rather it highlights the service component of tangible product.

Amazon.com keeps its customers loyal through its customer service. The prompt and satisfactory explanation and action regarding any order whether in transit or misplaced makes the customers truly loyal to the company. Clients are made satisfied and wowed about their service via their up-to-date information that relieves the customer from anxiety. The orders that are made through express delivery can be tracked from the port of original departure till the last port of destination (via DHL's tracking system integrated with customer's amazon.com account) and until the package reaches the customer's doorstep. The customers while ordering can also get to look inside the books online to have an idea on the content and the company lives up to their brand promise of replying within 6 to 12 hours, with a quicker and detailed reply even before the stipulated time of 6 to 12 hours of feedback upon every inquiry. Each letter is carefully written using the business communication strategies of dealing with the customers without making them unhappy.

The Sheraton Hotels and Resorts Worldwide ventured into making their unhappy/dissatisfied customers loyal with their "WOW" concept of service since its inception in 2002. The disgruntled guest when expresses dissatisfaction, the authority tries to solve it immediately by showing a goodwill gesture. Suppose, if the tea at the lobby café turns cold when served; the lobby café attendant not only replenished the order with a new coffee, $\mathrm{s} /$ he delights the guest by extending an order of cookie free with the compliments of the house. Similarly, if any guest mistakenly even forgets to switch off the DND (do not disturb) sign and orders room service a pet bottle of mineral water and the room service delivery goes back after seeing the DND sign and the guest demands apology even when the guest is at fault, the authority shows that they care about every guest they promise to take care by giving one carton of mineral water bottle free. The WOW budget for extraordinary service gives every individual working for the hotel the discretion of wowing the guest (Here WOW stands for: What's the problem? Own 
it and solve it! Wow the guest!)

From the above discuss it is clearly appeared that embedded service is a decisive in attracting customers irrespective of nature of the offering. Certainty it (service) has become an effective means of competitive advantage.

\section{Emerging Issues in Service}

In the new millennium, the nature of service has been changing rapidly due to the increased customer integration into the core of the business, customization and so on. Information technology has appeared as the key enabler of increased customer empowerment. Advances in information technology (IT) have reduced the life-cycle of products and dramatically changed the way in which business is managed in the new economy [10]. Worldwide people are currently connected to the Internet. Internet facilitates customer for higher degree of selfservice or customization while selecting their products [11]. Electronic mass media is playing a vital factor in empowering customers, too. The new state of condition is characterized by both the opportunity and the challenge. In several occasions, it has been so observed that, it is pretty difficult even to differentiate the services provided by many organizations. For example, in China, Haier, Midea and Gree - the three local giant home appliance producers offer similar products with similar service promises. Often customers find themselves in a point of indifference. Likewise in Bangladesh, in mobile phone industry it is becoming more difficult to identify which mobile phone package is more desirable and which one provides real value to the customers because mobile telecommunication service providers like GrameenPhone and Banglalink are offering almost identical package in different brand names and using different slogans. These service providers are busy in grabbing their competitors' market share by massive marketing campaign instead of offering new service, which is simply a waste of huge financial and other resources. Therefore, the time has come for more intelligent and innovative service configuration for the informed customers. Innovation in service is the demand of the new millennium. In addition to innovation, there are a range of associated issues which are equally critical and need systematic addressing.

Innovation has become an essential element of firms' competitive proposition. In many organizations innovation is at the top of the agenda. In highly globalized economy, it has become the key force for growth, competitiveness and economic development; through innovation an enterprise enhance their productivity and meet the increasing and constantly changing market demand, and countries thereby achieve sustainable economic growth [12].
It is widely recognized and appreciated that the ability to innovate can change the fundamental rules of competition [9]. The capability to innovate and to bring innovation successfully to market will be a crucial determinant of the global competitiveness of nations over the coming decades [12]. According to Muller et al., development of innovative capabilities is the only means by which companies can sustain a competitive advantage [13]. It is very much implied that the extent an offer is differentiated that is innovative and creative the greater is the chance of sustainable competitive advantage [14]. Innovation promotes growth of a firm through the development of competence-enhancing products, processes and services [15].

An institutional approach is equally important in configuring an effective service. Since the service function of a firm concerns and interacts with almost every activity or part or segment of the firm [10], thus, it needs a holistic approach [15] by incorporating all segments of an organization. The blue ocean strategy proposes to align entire system of a firm along with all of its resources all its resources in pursuit of differentiation and lost cost in order to ensure competitiveness in long-term [16].

The influence of technology is a never ending story. Technological advances influence the growth of service directly; particularly in the case of independent service offering and being a part of the total product package, etc. Thus, Service has become a business essential in manufacturing [17] as well as the foundation for the new product development. For example, Singer in Bangladesh provides after sale service to the customers in the form of repairing and maintenance, installation, training and development. It is possible to book air ticket in ChinaEastern Airline through internet. In all Chinese universities, students are given a Digital Student Card. This card can be used for multi-purposes, such as a library card, debit card in the dinning room and medical centre, bank instrument, etc. Consequently, service in conjunction with product and service provides customers an augmented service that is a real value. When service is added with the physical product or with another service, then a new offer is created.

There is another significant change in the global economy-the increased influence of knowledge across the world. Drucker mentioned that "We are moving to a society in which the basic resources of economy is knowledge, instead of capital, labor and natural resources" [18]. According to Stewart, "Knowledge has become the preeminent economic resources-more important than raw material; more important, often than money. Considered as an economic output, information and knowledge are more important than automobiles, oil, steel, or 
any of the products of the industrial age" [19]. The knowledge is equally important in the individual organizational level. It (knowledge) is the most strategically important resources of the business [20] and also the strategic determinants in success and failure of the business. The competitive advantage of the firms can be undercut overnight due to the new knowledge of the competitors. Market Leadership, size, name, recognition structure no longer guarantee the survival [21] even the skill and core competency cannot ensure that the firms will be able to capitalize on the new opportunity and tackle new challenges. Organizations develop their service package according to the expectations of the customers. Closer as the service to the customers' expectations, more popular is the offer. For example, at Singer Bangladesh, embedded service is the key factor in their growing popularity. Their service promise provides a sense of security to their customers. As the time passes, service providers modify their service package according to the changing expectations of the customers. Knowledge is the key player in this case. Knowledge not only provides an idea about the desired offer but also the desired service innate the product. While developing new offers, organisations have to develop their own competency and expertise to materialize the expectations of the customers. Thus, knowledge has the dual role within the

Table 6. The implications of emerging issues in service.

\begin{tabular}{|c|c|}
\hline Emerging Issues & Strategic Implications \\
\hline Information technology & $\begin{array}{l}\text { Empowered customer; intense customer } \\
\text { involvement; shared information; similar } \\
\text { offers and shorter product lifecycle, etc. }\end{array}$ \\
\hline Holistic approach & $\begin{array}{l}\text { Institutional involvement; capacity de- } \\
\text { velopment, efficient alignment of re- } \\
\text { sources, system and activities; intensive } \\
\text { people integration and interaction, etc. }\end{array}$ \\
\hline Innovation and creativity & $\begin{array}{l}\text { Differentiated offers; greater access to } \\
\text { customer information; capacity to inno- } \\
\text { vate; useful means of sustainable com- } \\
\text { petitive advantage and so on. }\end{array}$ \\
\hline Indispensability of service & $\begin{array}{l}\text { No product without embedded service; } \\
\text { attracting customers through attached } \\
\text { service, after sales service, customer sat- } \\
\text { isfaction and so forth. }\end{array}$ \\
\hline Technology & $\begin{array}{l}\text { New offerings; increased utility; greater } \\
\text { value to the customers and organization; } \\
\text { faster and efficient service, technological } \\
\text { capability development, new service idea, } \\
\text { effective communication, and so on. }\end{array}$ \\
\hline Managing knowledge & $\begin{array}{l}\text { Strategic assets to configure innovative } \\
\text { and intelligent offering; better customer } \\
\text { profiling; better market information; sus- } \\
\text { tainable source of competitive advantage, } \\
\text { development of distinctive capability of } \\
\text { the individuals as well as organizations } \\
\text { and so forth. }\end{array}$ \\
\hline
\end{tabular}

organization-developing distinctive capability for the firm which also is a unique source of competitive advantage; and getting access to the market and the customers' domain. The firm, which understands customers' needs, will be able to mix and match various products and services that commensurate with customers' specific needs.

\section{Other Essential Factors of Innovative Service}

In the earlier section we found a number of issues which are extremely crucial in configuring an effective and attractive service. These issues have a number of strategic implications (Table 6). These issues directly related with organization culture, leadership, people (employees and customers) integration, system, activities, capacity development, market and customer information and so on. Without a dynamic and accommodating organization environment it is impossible to conceive these strategic issues effectively. In this regards institutional initiatives are essential. The initiatives are as follows:

\subsection{Business Development Policy and Supporting Infrastructure}

Business development policy is imperative for overall business activities of an organization irrespective of nature. A general business development policy should be according to the very basic nature of the business. Supporting infrastructure (information technology, logistics, HR and administrative policy, etc.) is equally important since success of business development policy depends on it.

\subsection{Innovative Organization Culture}

Innovative organization culture is simply crucial in making an organization innovative. In this connection a support from top management is needed along with other facilities like research and development, training and development, creating a learning culture with a shared vision, encouraging employee participation in service development. People must be at the heart innovative organization culture. Creative individuals are the main impetus of innovation process. The organization should recruit creative and innovative personnel. It is also necessary to make innovation is the requirement of the job description otherwise people will lose their urge for innovation. Continuous up-gradation of knowledge-base through knowledge initiatives; alignment of resources in the line of business development policy and free flow of information and ensuring access to the knowledge database by the workers are simply vital.

\subsection{A Total Competency-Right Skill, Right Time Right Place and Right Offer}

In the knowledge era, businesses are facing a dramatic 
new competitive environment, which is characterized by abundant dynamic opportunities, possibilities and challenges. For the competitive advantage 'right knowledge' along with other factors, e.g. right time, place, etc. matters the most [21]. In service, workers, process and customers are directly involved since production and consumption take place simultaneously. Therefore, the right skill with the right knowledge is a bare need to ensure right time and place. People are the most inevitable and valuable resource due to their intellectual input. An integrated approach of human resource management is needed in order to develop organizational competency. Hamel and Prahalad mentioned that managers nurture and develop competitive intelligence at every level of the organization in order to build the firm's competitive advantage [22]. Collective individual competency and capacity would convert into organizational competency in an organizational setting. This organization competency refers to the capability to produce or configure right service for the clients. In future business success will depend on an organization's ability to imagine and/or create a need. Innovation in services reflects the creativity of the human mind (knowledge) [23].

\subsection{Research and Development}

Research and development is the fundamental source of innovative offers. The innovators must have the all types of resources to play with their ideas. Unless the ideas are nurtured, implemented and tested those ideas will not bring any result, and innovators will not be motivated. Simultaneously, an organization will deprive itself from getting the benefit from innovation and creativity.

\subsection{Social Network for People Integration}

Innovative service is the result of "innovative service concept" and obviously it starts from in depth understanding the customers' needs. Similarly, it is also required to have a holistic understanding of the customers, too. For knowledge regarding the market and customers, a continuous interactive mechanism is needed, i.e. a social network, between the firms and the market. This network supplies information on buyers' value chain, i.e. total needs of the buyers for today and tomorrow. In the boundary-less virtual world network between customers and the organization has become an essential precondition for innovation, acquiring new knowledge on customers and market, and to attain the capabilities in serving the customers. A technology based network is equally important. For example, the competitive advantage for courier service companies like Federal Express or DHL significantly depends on the technology based network. It is essential, particularly for tracking during transit. This network not only helps in tracking the package but also to integrate people in all steps of the service delivery process. Furthermore it (technology based network) demonstrates the service delivery process to the customers, which creates a positive impression to them.

\section{Role of Government in Service Innovation}

Although it may be presumed that innovation is a simple organization effort yet the real fact is that it is the function of micro and macro economic factors. Earlier, organizational aspect more or less has been addressed. It is also crucial to see the macro-economic factors particularly the role of government in encouraging innovation. By nature innovation is a complex social process; many public and private institutions, knowledge bodies, scholars, policy makers, etc. are directly or indirectly involved in this innovation process. The innovation performance of a country significantly depends on how these actors interface each other in this innovation process [12]. Even though government cannot play a direct role, but obviously can play an indirect yet vital role in fostering innovation. The environment for innovation can be created improving business climate, establishing well-balanced IPR intellectual property right systems, investing in human capital, investment in research and development, provide more support to small and medium enterprises (SMEs), acquires, creates, disseminates, and uses knowledge, and so on. In this connection the Chinese experience may provide useful insight. Promoting sustainable development through innovation appeared as a huge challenge to the government of China; to cope with this challenge, the government of China introduced four major measures: 1) proactively offer guidance and support to promote indigenous innovation; 2) gradually establish a technology innovation system with enterprises as the cornerstone, the market as the guide, and industry, academia, and research institutions fully integrated; 3) provide more support to small and medium enterprises (SMEs); and 4) ensure better protection of intellectual property rights (IPR) [12]. The government of Bangladesh has given more emphasis in its running 'five years plan' for the development of infrastructure for the service sector.

\section{Conclusions}

In the customer empowered market, customers expect that firms will delight their customers with their innovation and creativity. By ensuring a continuous flow of innovation, a firm can attain competitive advantage and sustainability. In contrast, perhaps it (innovation) is the single most destructive force in an industry [24]. It can destroy organization's capabilities. The dual nature of innovation necessitates careful managerial attention. Today's success formula might not be effectual in near fu- 
ture. The present state of competency may not be sufficient for tomorrow's success. Firms need to balance the competence-enhancing and competence-destroying forces in their innovation endeavors. Organisations need a continuous upgrading in their armor and arsenals through acquiring the latest knowledge and the new competency along with the new technology. Otherwise, service will lose is ability to enhance the true value to the customers, and the organization will be in a more vulnerable flux in attaining the competitive edge.

\section{REFERENCES}

[1] S. Vandermerwe and J. Rada, "Servitization of Business: Adding Value by Adding Service," European Management Journal, Vol. 6, No. 4, 1988, pp. 314-324. doi:10.1016/0263-2373(88)90033-3

[2] A. Smith, "The Wealth of Nations," Prometheus Books, Essex, 1776.

[3] S. Desmet and R. V. Dierdonck, "Service in World Economy," In: B. V. Looy, R. V. Dierdonck and P. Gemmel, Eds., Services Management: An Integrated Approach, Prentice Hall, Upper Saddle River, 1998, pp. 45-58.

[4] UNCTAD Handbook of Statistics, United Nations Conference on Trade and Development, Geneva, 2010.

[5] Development and Globalization: Facts and Figures 2008, United Nations, New York and Jeneva, 2008.

[6] C. Lovelock, S. Vandermerwe and B. Lewis, "Services Marketing: A European Perspective," Prentice Hall Europe, Hemel Hempstead, 1999.

[7] J. B. Quinn and C. E. Gagnon, "Will Services Follow Manufacturing in Decline?" Harvard Business Review, November 1986, pp. 95-103.

[8] C. Gronroos, "Service Management and Marketing: A Customer Relationship Management Approach," Wiley, London, 2000.

[9] S. Desmet, R. V. Dierdonck and B. V. Looy, "Servitisation: The Blurring Boundaries between Manufacturing and Services in Services Management: An Integrated Approach," In: B. V. Looy, R. V. Dierdonck and P. Gemmel, Eds., Services Management: An Integrated Approach, Prentice Hall, Upper Saddle River, 1998, pp. 33-44.

[10] J. Kandampully, "Innovation as the Core Competency of a Service Organisation: The Role of Technology, Knowledge and Networks," European Journal of Innovation
Management, Vol. 5, No. 1, 2002, pp. 18-26. doi:10.1108/14601060210415144

[11] R. Hallowell, "Scalability: The Paradox of Human Resources in e-Commerce," International Journal of Service Industry Management, Vol. 12. No. 1, 2001, pp. 34-43. doi:10.1108/09564230110694820

[12] Q. Fan, K. Li, D. Z. Zeng, Y. Dong and R. Peng, "Innovation for Development and the Role of Government: A Perspective from the East Asia and Pacific Region," The World Bank, Washington DC, 2009.

[13] A. Muller, L. Välikangas and P. Merlyn, "Metrics for INnovation: Guidelines for Developing a Customized Suit of Innovation Metrics," Strategy \& Leadership, Vol. 33, No. 1, 2005, pp. 37-45. doi:10.1108/10878570510572590

[14] M. E. Porter, "Competitive Advantage," The Free Press, New York, 1985.

[15] K. Debackere, B. van Looy and P. Papastathopoulou, "Managing Innovation in a Service Environment in Services Management: An Integrated Approach," In: B. V. Looy, R. V. Dierdonck and P. Gemmel, Eds., Services Management: An Integrated Approach, Prentice Hall, Upper Saddle River, 1998, pp. 387-405.

[16] W. Chan Kim and Renee Mauborgne, "Blue Ocean Strategy: How to Create Uncontested Market Space and Make Competition Irrelevant," Harvard Business School Press, Boston, 2005.

[17] V. A. Zeithaml and M. J. Bitner, "Services Marketing," McGraw-Hill, New York, 1996.

[18] P. F. Drucker, "The Post Capitalist Society," ButterworthHeinemann, Oxford, 1993.

[19] T. A. Stewart, "Intellectual Capital: The New Wealth of Organizations," Doubleday, London, 1997.

[20] M. H. Zack, "Developing a Knowledge Strategy," California Management Review, Vol. 41, No. 3, 1999, pp. 125-145.

[21] T. Housel and A. H. Bell, "Measuring and Managing Knowledge," McGraw-Hill Irwin, New York, 2001.

[22] G. Hamel and C. K. Prahalad, "Strategic Intent," Harvard Business Review, May-June 1989, pp. 63-76.

[23] P. Z. Pilzer, "Unlimited Wealth: The Theory and Practice of Economic Alchemy," Crown Publishers, New York, 1990.

[24] J. Kay, "Foundations of Corporate Success," Oxford University Press, Oxford, 1993. 